\title{
Experimentally and analyzed property of carbon fiber reinforced thermoplastic and thermoset plates
}

\author{
Mitsuhiro Okayasu ${ }^{1}$, Yuki Tsuchiya ${ }^{1} \&$ Hiroaki Arai $^{2}$ \\ ${ }^{1}$ Graduate School of Natural Science and Technology, Okayama University, 3-1-1 Tsushimanaka, Kita-ku, \\ Okayama, 700-8530, Japan \\ ${ }^{2}$ SPIC Corp. 125 Souya, Susono, Kanagawa, 257-0031, Japan \\ Correspondence: Mitsuhiro Okayasu, Graduate School of Natural Science and Technology, Okayama University, \\ 3-1-1 Tsushimanaka, Kita-ku, Okayama, 700-8530, Japan. E-mail: okayasu@okayama-u.ac.jp
}

Received: May 12, 2017

Accepted: May 24, 2017

Online Published: June 30, 2018

doi: $10.5539 /$ jmsr.v7n3p12

URL: https://doi.org/10.5539/jmsr.v7n3p12

\begin{abstract}
The tensile and fatigue properties of long unidirectional (UD) and crossply (CR) carbon fiber reinforced plastics (CFRPs) were investigated. The CFRPs in this study were fabricated from $60 \% \mathrm{CF}$ and various resins: epoxy, polyamide (PA6), polyphenylene sulfide (PPS), and polyether ether ketone (PEEK). The ultimate tensile strength $\sigma_{\mathrm{UTS}}$ of Epoxy-CFRP was found to be about twice that of PEEK-CFRP. Relatively high tensile strengths were found for PPS- and PA6-CFRP in the thermoset resin group, although these were still only about $85 \%$ of the strength of epoxy-CFRP. The tensile and fatigue strengths of the CR-CFRPs were less than half those of the UDCFRPs, even though high ductilities were found for the CR-CFRPs. These high ductilities can be attributed to the crosslinking fiber effect and the low proportion of CFs in the loading direction. The $\sigma_{\mathrm{UTS}}$ values of CFRPs depend not only on the tensile strengths $\sigma$ and volume fractions $V$ of CF and resin (i.e., through the conventional compound law $\sigma_{\text {UTS }}=\sigma_{\text {fiber }} V_{\text {fiber }}+\sigma_{\text {resin }} V_{\text {resin }}$ ), but also on several material properties, including the wettability of the CF by the resin. On the basis of the material properties, the ultimate tensile strengths of various UD- and CR-CFRPs were well estimated numerically through a statistical analysis, which afforded better estimates than those obtained from the compound law.
\end{abstract}

Keywords: CFRP, Carbon fiber, Tensile strength, Numerical analysis, Thermoplastic resin

\section{Introduction}

Owing to the high demand for materials that are both lightweight and strong, carbon fiber reinforced plastics (CFRPs) have become widely employed in various engineering applications, including the aerospace and automotive industries. A CFRP consists of carbon fiber and resin, which are combined by hot pressing and injection molding processes. In recent years, the production volume of CFRPs has increased dramatically (Kirihara et al., 2011), with more than 1 million tonnes of such composites being manufactured in Europe each year (Bos, 2002). However, several technical issues remain with these materials, such as their poor connectability and recyclability. The latter constitutes an environmental problem, since post-use CFRPs are considered as waste and generally go to landfill (Belingardi, Koricho, \& Martorana, 2011). Although it is well known that thermoset resins are difficult to recycle, epoxy-based CFRPs are widely used owing to their high strength. To deal with the poor recyclability of CFRPs, several recycling technologies have been proposed. Ogi et al. (2007) have introduced a recycling method based on a process in which an epoxy-based CFRP (Epoxy-CFRP) with long carbon fibers is crushed to produce particles about $200 \mu \mathrm{m}$ in diameter, which are then mixed with thermoplastic resin via injection molding, to give a short carbon fiber reinforced plastic. The mechanical properties of this recycled CFRP (rCFRP) with different weight fractions of short carbon fibers have been investigated. It was found that the tensile strength of the rCFRP increased as the CFRP content was increased up to $50 \%$, beyond which there was a reduction in tensile properties for rCFRP with higher fiber content. However, the maximum tensile strength of the $50 \% \mathrm{rCFRP}$ was still low, at only $82 \mathrm{MPa}$, limiting its range of application. A similar study has been performed on a recycled CFRP produced using CFRP crushed to give relatively large pieces, which were mixed randomly in different proportions with various resins (Okayasu \& Kondo, 2017). Two different sizes of crushed CFRP were used: $0.1 \mathrm{~mm} \times 0.007 \mathrm{~mm}$ (milled CFRP) and $30 \mathrm{~mm} \times 2 \mathrm{~mm}$ (chopped CFRP). The tensile strength of the resulting recycled material depended on both the proportion and size of the CFRP pieces. It increased with an increasing 
proportion of chopped CFRP, but decreased with an increasing proportion of milled CFRP. A high fracture strain was obtained for the material produced from milled CFRP as a result of the coalescence of existing microvoids.

In an alternative approach, natural fibers have been introduced in the production of thermoplastic composites, because of their low cost and eco-friendly and biodegradable characteristics $(\mathrm{Ku}$, Wang, Pattarachaiyakoop, \& Trada, 2011). Many types of natural fibers have been utilized in this way, such as hemp, jute, wood fiber, rice husks, and pineapple leaf fiber. However, one issue with natural fiber composites is their poor mechanical properties; for example, the tensile strength $\sigma_{\mathrm{f}}$ of hemp is about $690 \mathrm{MPa}$, which is only about $17 \%$ of the $\sigma_{\mathrm{f}}$ for CF (Taj, Munawar, \& Khan, 2007).

It is generally considered that thermoplastic resins have a technical advantage with regard to the recycling of CFRPs into new products (Uzawa et al., 2009). This is because thermoplastic CFRPs can be re-melted by heating to a certain temperature (Eguemann et al., 2014). The resulting recyclability allows minimization of waste (Pannkoke, Oethe, \& Busse, 1998). However, the mechanical properties of thermoplastic CFRPs are potentially poorer than those of thermoset CFRPs because of the low strength of thermoplastic resins. A representative thermoplastic resin is polyether ether ketone (PEEK), which is employed in aircraft structural applications (A. Suresh, A.P. Harsha, M.K. Ghosh, 2009). It is generally accepted that the tensile strength of a CFRP can be estimated from the compound law $\sigma_{\mathrm{UTS}}=\sigma_{\mathrm{f}} V_{\mathrm{f}}+\sigma_{\mathrm{r}} V_{\mathrm{r}}$, where $\sigma_{\mathrm{f}}$ and $\sigma_{\mathrm{r}}$ are the tensile strengths of the fiber and resin, respectively, and $V_{\mathrm{f}}$ and $V_{\mathrm{r}}$ are the corresponding volume fractions. It has been reported that the tensile strength of thermoplastic acrylonitrile butadiene styrene (ABS) resin is about $41 \mathrm{MPa}(\mathrm{J}-\mathrm{Z}$. Liang, 2005) which is lower than that of a thermosetting resin (epoxy). Ning et al. investigated the mechanical properties and failure characteristics of a CFRP made from ABS, and showed that the porosity of this CFRP led to inferior mechanical properties. In a previous study (Takahashi, 2007), an attempt was made to improve the mechanical properties of a CFRP based on a thermosetting resin and incorporating waste CFRP material. The target mechanical properties of the recycled CFRP were higher than those of the secondary structural parts of current automobiles. Even though there have been several investigations of the mechanical properties of thermoplastic CFRPs, there is an apparent lack of related information. A search of the Scopus database for "thermoplastic", "CFRP", and "mechanical property" retrieved only 25 academic papers. Therefore, in the present work, the tensile and fatigue properties of several thermoplastic CFRPs are investigated, and their tensile strengths were numerically analyzed.

\section{Materials and Experimental Procedure}

The mechanical properties of commercial unidirectional (UD) and crossply (CR) CF composites were investigated, with four resins being selected: one thermoset resin (epoxy) and three thermoplastic resins (polyamide (PA6), polyphenylene sulfide (PPS), and polyether ether ketone (PEEK)). Note that these thermoplastic resins are all employed in the automotive and aerospace industries; moreover, the PEEK resin can also be used at high temperatures. All of the CFRPs investigated in this study consisted of a resin together with a $60 \%$ CF content. Rectangular CFRP plates $(150 \mathrm{~mm} \times 150 \mathrm{~mm} \times 1 \mathrm{~mm})$ were fabricated using a hot pressing process. Figure 1a displays photographs and scanning electron microscopy (SEM) images of the CFRP plates, showing the CFs and matrix.

To investigate the mechanical properties of the CFRP samples, tensile and fatigue tests were conducted at room temperature using a screw-driven-type universal testing machine with $50 \mathrm{kN}$ capacity. Straight-shaped test specimens $(60 \mathrm{~mm} \times 10 \mathrm{~mm} \times 1 \mathrm{~mm})$ were used, with aluminum plates attached to the surface of the CFRP specimens to ensure strong adherence to the testing fixture (Figure 1b). The loading speed for the tensile test was fixed at $1 \mathrm{~mm} \mathrm{~min}^{-1}$ up to the fracture point. The stress and strain values were measured using a standard load cell and strain gauge, respectively. The fatigue properties of the CFRPs were examined by low-cycle fatigue tests, in which a tensile-tensile loading was applied to the test specimens at a load ratio of 0.1 and a frequency of $1 \mathrm{~Hz}$ until either the specimen fractured completely or the endurance limit was reached at $10^{5}$ cycles. To examine the wettability of the CF by the resin, a three-point bending test was performed using a rectangular UD-CFRP plate $(50 \mathrm{~mm} \times 10 \mathrm{~mm} \times 1 \mathrm{~mm})$, where the peeling strength (bonding strength) between the CF and the resin was examined (Figure 1c) and it was found that the failure grew as a consequence of fiber/matrix interfacial debonding. 
(a) UD- and CR-CFRP

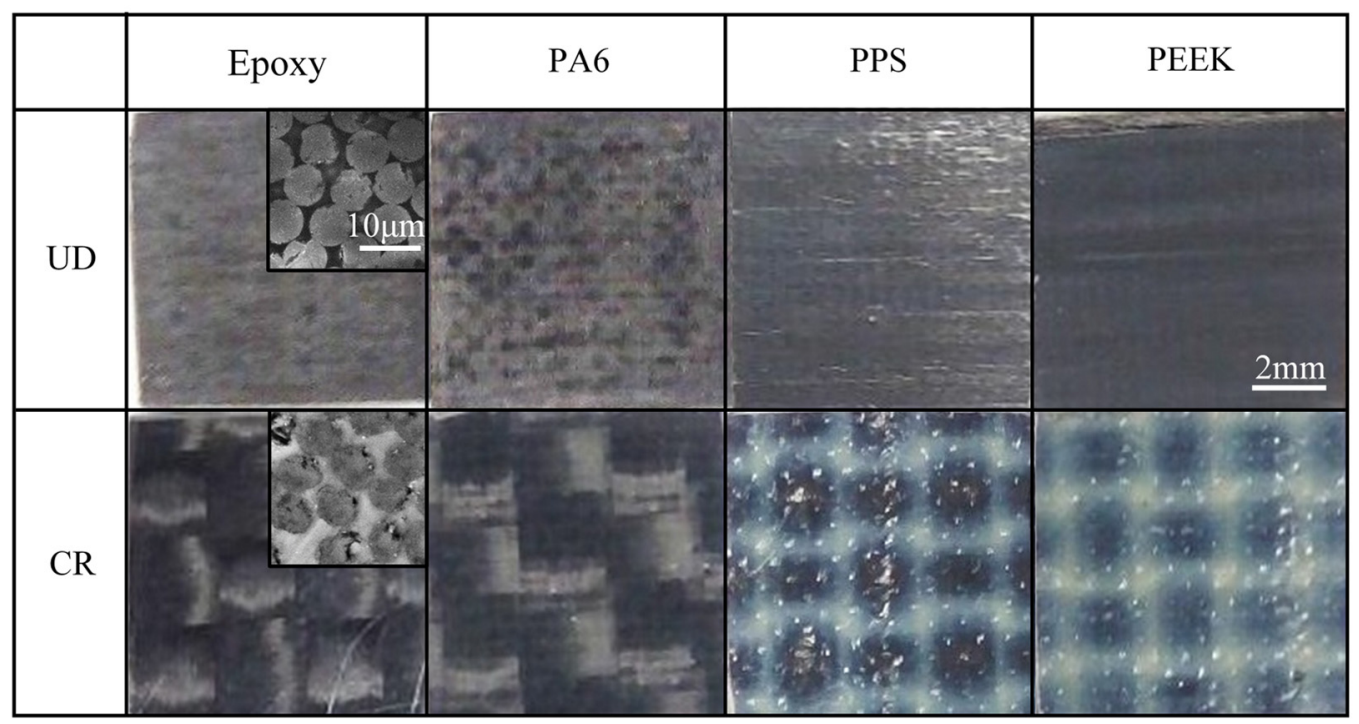

(b) Tensile and fatigue test specimen

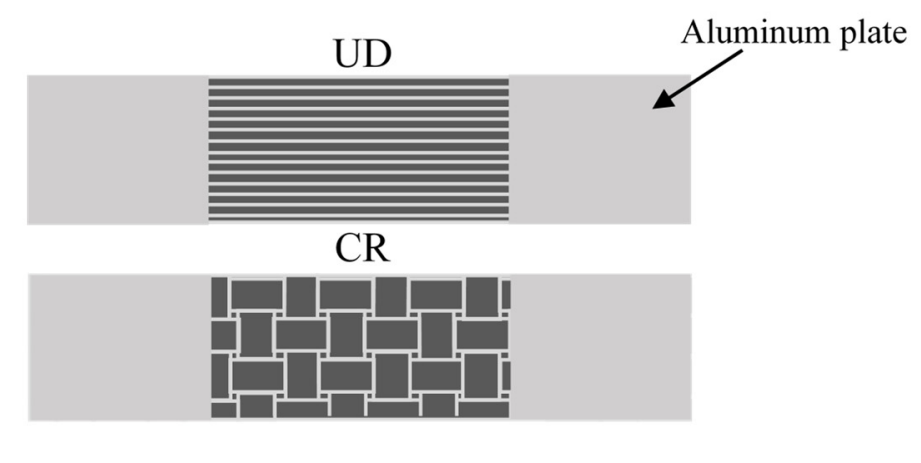

$$
t=1 \mathrm{~mm}
$$

(c) Three-point bending test specimen
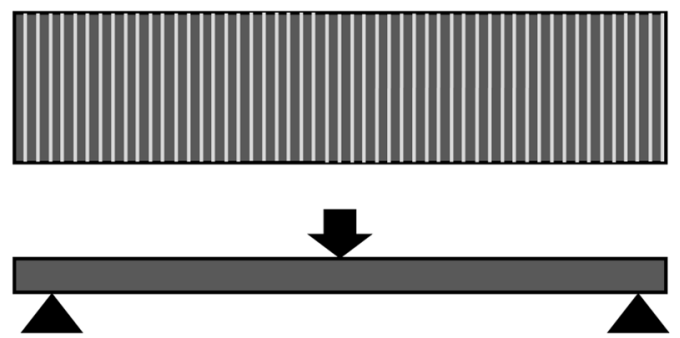

Figure 1. (a) Photographs of the CFRP samples, showing the carbon fibers and matrix. (b) Schematic illustrations of the tensile and fatigue specimens. (c) Schematic illustration of the three-point bending test

\section{Results}

\subsection{Mechanical Properties}

Figure 2 shows the relationship between the tensile stress and strain of thermoset and thermoplastic CFRPs with (a) unidirectional and (b) crossply CF composite. As can be seen, the stress-strain relations exhibited different trends, with regard to, for example, elastic constant, strength, and ductility. Based on these stress-strain curves, the ultimate tensile strength $\sigma_{\text {UTS }}$ and strain to failure $\varepsilon_{\mathrm{f}}$ for the CFRPs are summarized in Figure 3 . It is clear that the tensile strength of Epoxy-CFRP was higher than that of thermoplastic CFRPs for both unidirectional and crossply fiber composites, which can be attributed to the high strength of the epoxy resin. A significant reduction 
in $\sigma_{\mathrm{UTS}}$ was obvious for UD-PEEK-CFRP in the UD-CFRP group; for example, the $\sigma_{\mathrm{UTS}}$ of UD-PEEK-CFRP was about half that of UD-Epoxy-CFRP. The tensile strengths of UD-PPS- and UD-PA6-CFRP (about $2000 \mathrm{MPa}$ ) were relatively high among the thermoplastic CFRPs, although still about $10 \%$ lower than that of UD-EpoxyCFRP. The tensile strengths of UD-CFRPs were overall higher than those of CR-CFRPs. This can be ascribed to a larger volume fraction of carbon fiber setting in the loading direction: $60 \%$ for UD-CFRPs and $30 \%$ for CRCFRPs. In contrast, the fracture strains $\varepsilon_{\mathrm{f}}$ of CR-CFRPs were overall higher, approximately 1.5 times as high as those of UD-CFRPs. These high $\varepsilon_{\mathrm{f}}$ values of the CR-CFRPs may be attributed not only to the low volume fraction of CF setting in the loading direction but also to the crosslinking-fiber effect (see Figure 4), which will be discussed in the following paragraph. It should be noted that, as with the results for $\sigma_{\mathrm{UTS}}$, the $\varepsilon_{\mathrm{f}}$ of UD-PEEK-CFRP was also at a lower level.

(a) UD-CFRP

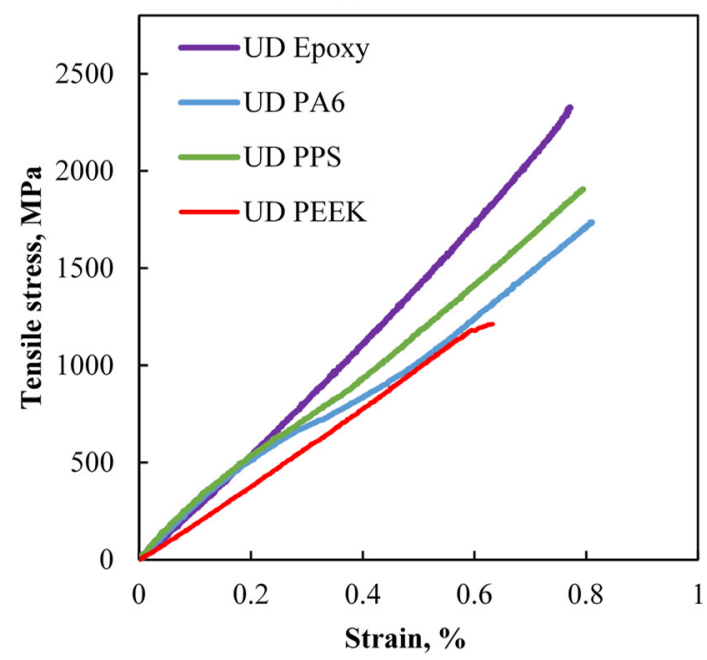

(b) CR-CFRP

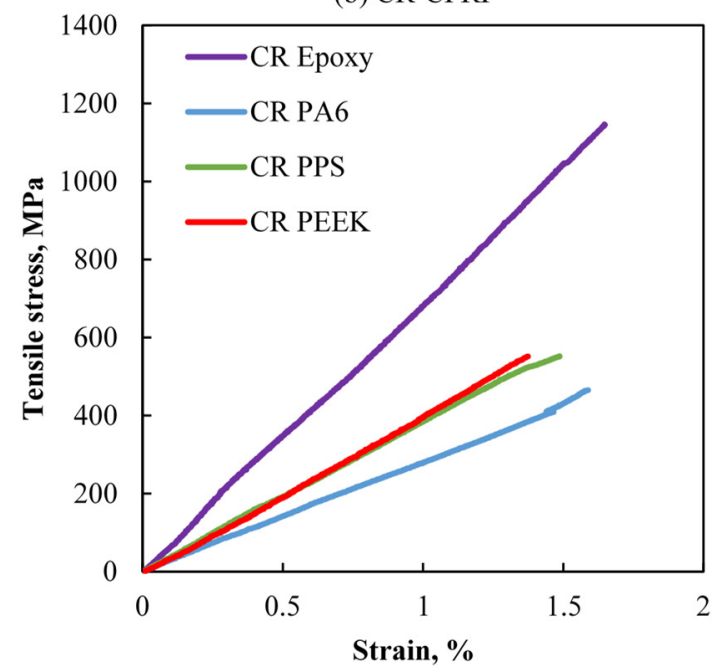

Figure 2. Representative stress-strain curves of thermoset and thermoplastic CFRPs: (a) unidirectional CF composites; (b) crossply CF composites

To interpret the crosslinking-fiber effect, illustrated in Figure 4, a tensile test was carried out using CR-EpoxyCFRP and CR-PPS-CFRP specimens in which the carbon fibers were set in a direction at $45^{\circ}$ to the loading direction. It was found that the $\varepsilon_{\mathrm{f}}$ values of Epoxy-CFRP and PPS-CFRP increased to $15 \%$ and $18 \%$, respectively, which are over seven times higher than those of the corresponding $90^{\circ} \mathrm{CR}-\mathrm{CFRP}$ specimens (Figure 3b). A similar approach was adopted in tests by Curtis (R.T. Curtis, 1984), and one of his results was that $90^{\circ}$ specimens showed a linear stress - strain relationship at low strain, while $45^{\circ}$ specimens showed a nonlinear relationship at high strain. High strain values were obtained for recycled CFRP, for example, $\varepsilon_{\mathrm{f}}=16 \%$, although the $\sigma_{\mathrm{UTS}}$ values were as low as $100 \mathrm{MPa}$ (Ogihara \& Takeda, 1995).

To further understand the tensile properties of these CFRPs, the $\sigma_{\text {uTs }}$ values of their pure resin components were examined. Figure 5 shows the relationships between the $\sigma_{\mathrm{uts}}$ values of the resins and those of the corresponding CFRPs. As can be seen, a clear correlation was found, especially for the CR-CFRPs, although there was a low correlation rate of 0.37 for the UD-CFRPs owing to the low $\sigma_{\text {UTS }}$ of PEEK. This may lead to the different material properties of UD-PEEK-CFRP, which will be discussed later in this paper.

Figure 6 shows the relationship between the stress amplitude and the number of cycles to failure (the $S_{\mathrm{a}}-N_{\mathrm{f}}$ curve) for the CR-CFRPs. Note that the arrows on the $S_{\mathrm{a}}-N_{\mathrm{f}}$ curves indicate those specimens that did not fail within $10^{5}$ cycles. It can be seen that the $S_{\mathrm{a}}-N_{\mathrm{f}}$ curve for Epoxy-CFRP was located at a higher level than those for the thermoplastic CFRPs. On the other hand, similar $S_{\mathrm{a}}-N_{\mathrm{f}}$ curves were obtained for all of the thermoplastic CFRPs; see the endurance limits $\sigma_{\mathrm{e}}$ at $10^{5}$ cycles, all of which are of the order of $100 \mathrm{MPa}$. The $\sigma_{\mathrm{e}}$ values of the thermoplastic CFRPs are about half that of Epoxy-CFRP. The fatigue strength shows a similar trend to $\sigma_{\mathrm{UTS}}$. To understand the fatigue strength more clearly, the $S_{\mathrm{a}}-N_{\mathrm{f}}$ curves were analyzed quantitatively in terms of a powerlaw relationship between applied stress and number of cycles to failure:

$$
S_{\mathrm{a}}=\sigma_{\mathrm{f}} N_{\mathrm{f}}^{-b},
$$


where $\sigma_{\mathrm{f}}$ is the fatigue strength coefficient and $b$ is the fatigue exponent. In this case, the high fatigue strength is related to the low value of $b$ and the high value of $\sigma_{\mathrm{f}}$. The values of $\sigma_{\mathrm{f}}$ and $b$ for the CFRPs, obtained by leastsquares analysis, are listed in Table 1 . In the present case, the $\sigma_{\mathrm{f}}$ and $b$ values for Epoxy-CFRP indicate a high fatigue strength, while low fatigue properties were obtained for the thermoplastic CFRPs, with lower $b$ and lower $\sigma_{\mathrm{f}}$ values, i.e., with a lower slope of the $S_{\mathrm{a}}-N_{\mathrm{f}}$ curve.

Table 1 Fatigue strength coefficients and fatigue exponents of CR-CFRPs

\begin{tabular}{ccccc}
\hline & Epoxy $(\mathrm{CR})$ & PA6 (CR) & PPS (CR) & PEEK (CR) \\
\hline$\sigma_{\mathrm{f}}, \mathrm{MPa}$ & 260.2 & 147.8 & 132.6 & 130.8 \\
$b$ & 0.037 & 0.078 & 0.04 & 0.047 \\
\hline
\end{tabular}

(a) UD-CFRP
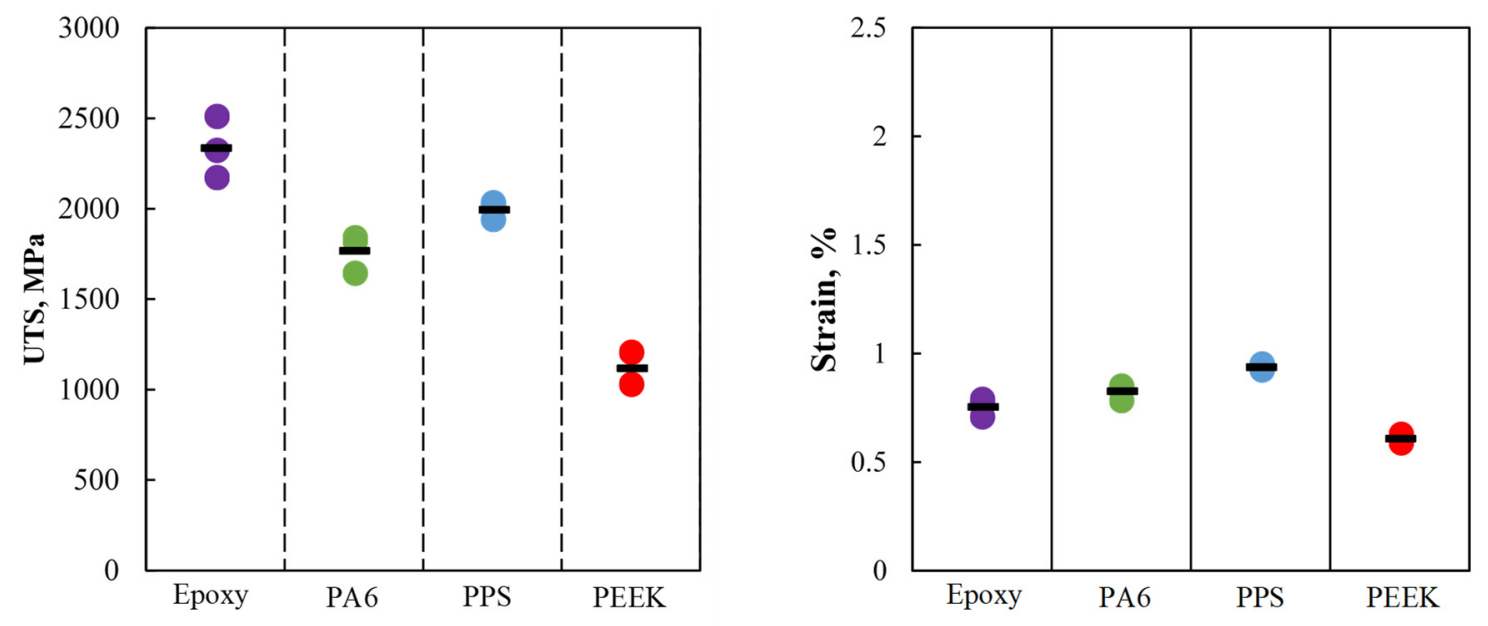

(b) CR-CFRP
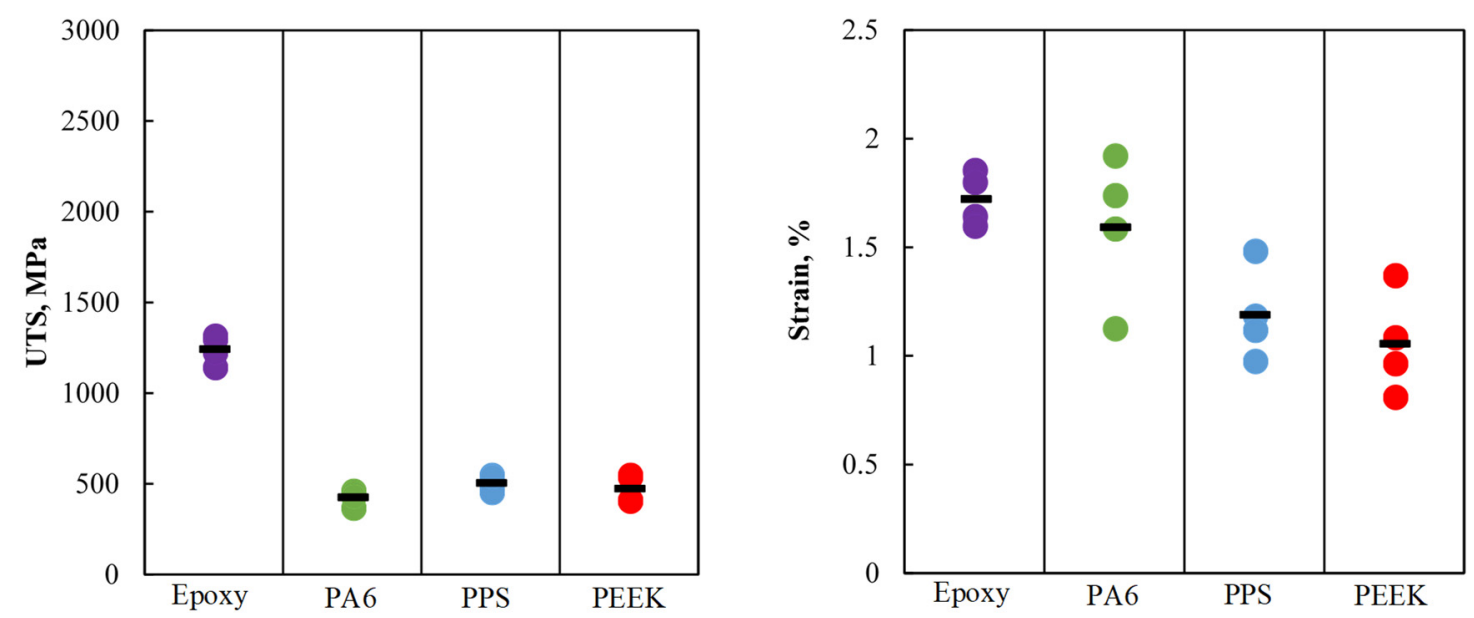

Figure 3. (a, b) Ultimate tensile strength $\sigma_{\mathrm{UTS}}$ (UTS) and strain to failure $\varepsilon_{\mathrm{f}}$ of various CFRPs: (a) UD-CFRPs; (b) CR-CFRPs 


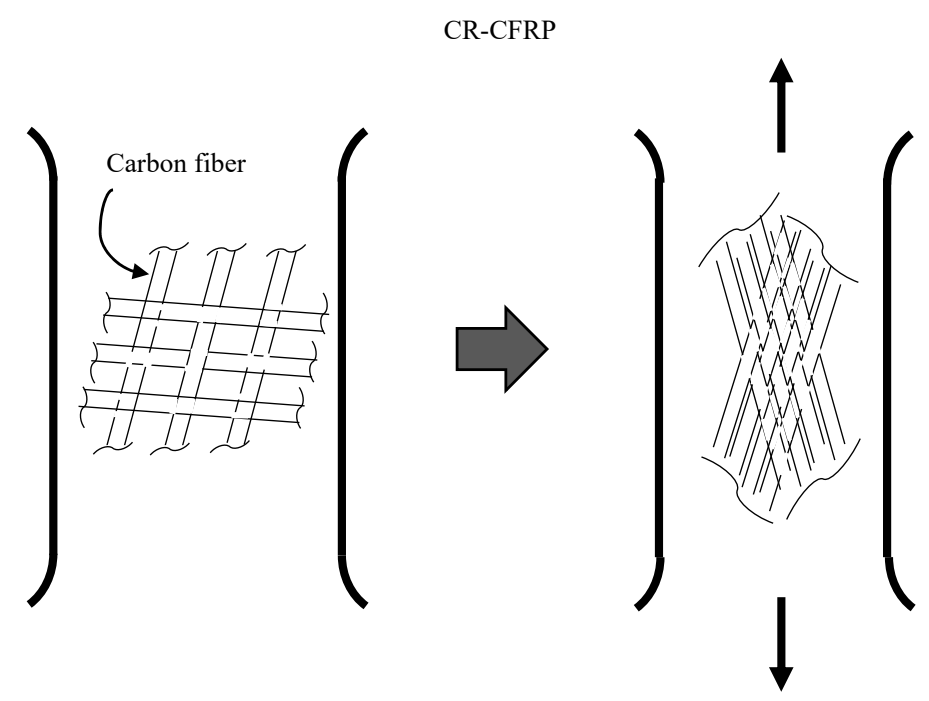

Figure 4. Schematic illustration of the crosslinking fiber effect leading to the high ductility of CFRPs
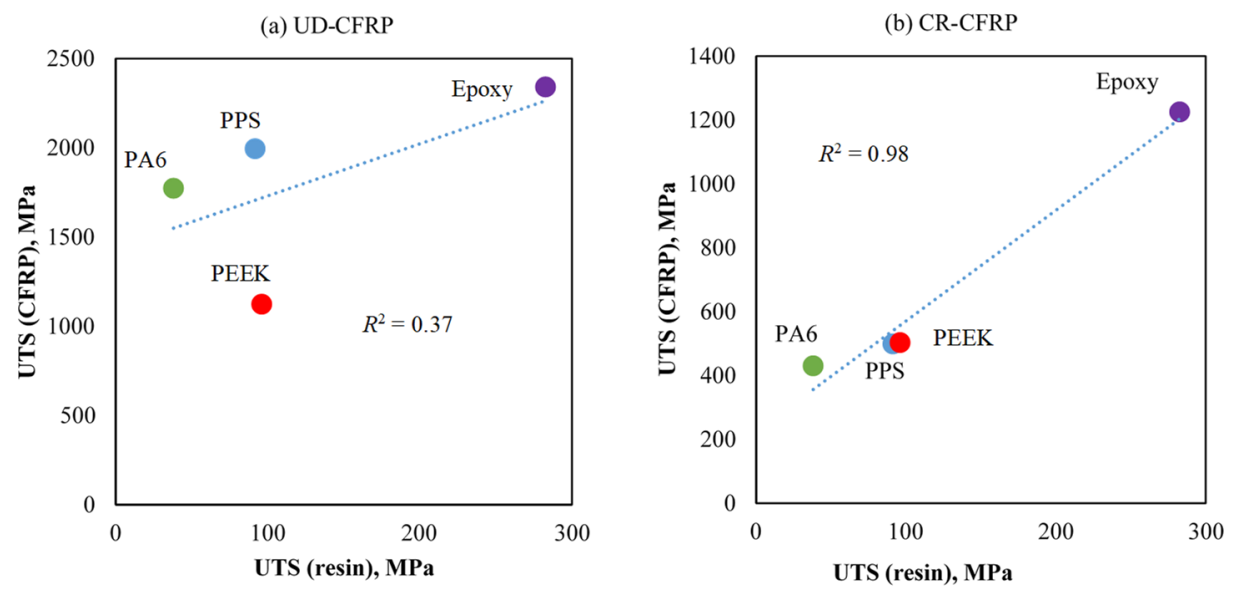

Figure 5. Relationship between $\sigma_{\mathrm{UTS}}$ values of resins and those of the corresponding CFRPs: (a) UD-CFRPs; (b) CR-CFRPs

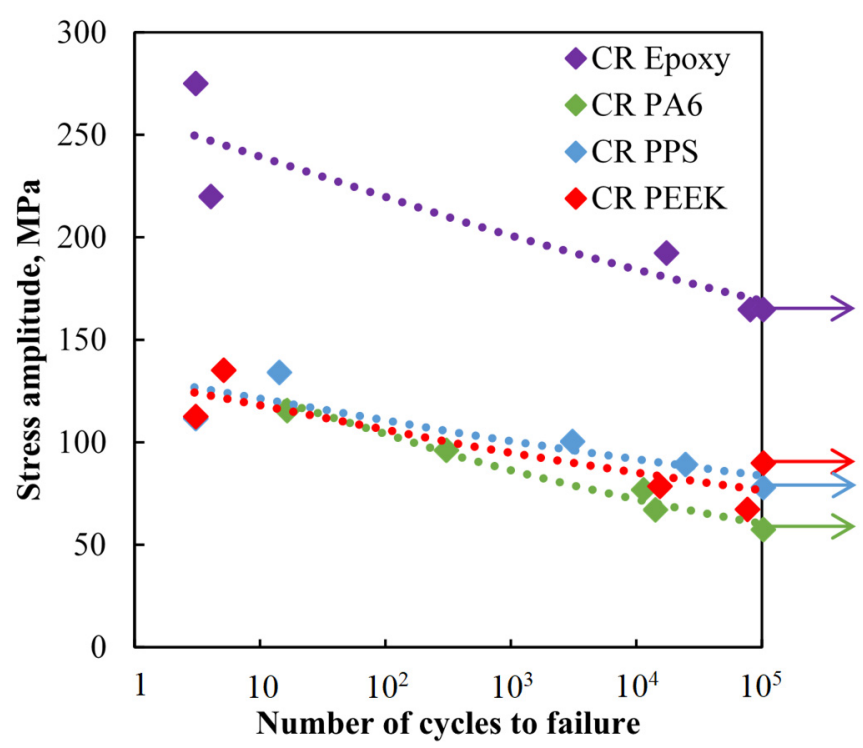

Figure 6. Relationship between stress amplitude and number of cycles to failure $\left(S_{\mathrm{a}}-N_{\mathrm{f}}\right.$ curve $)$ for CR-CFRPs 


\section{Discussion}

To estimate the ultimate tensile strengths of the CFRPs, a compound-law analysis of the tensile strength was carried out, using the relationship $\sigma_{\mathrm{UTS}}=\sigma_{\mathrm{f}} V_{\mathrm{f}}+\sigma_{\mathrm{r}} V_{\mathrm{r}}$ as given in Section 1. The tensile strengths of the carbon fiber and resins were $\sigma_{\mathrm{f}}=3530 \mathrm{MPa}(\mathrm{CF})$ and $\sigma_{\mathrm{r}}=283 \mathrm{MPa}$ (Epoxy), $38 \mathrm{MPa}$ (PA6), $91 \mathrm{MPa}$ (PPS), and $96 \mathrm{MPa}$ (PEEK). The volume fractions of UD-CFRP were estimated as $60 \%$. The $\sigma_{\mathrm{UTS}}$ values approximated by the compound law using these material properties are presented in Figure 7, in which the $\sigma_{\mathrm{UTS}}$ values obtained from the tensile test are also plotted. As can be seen, the estimated $\sigma_{\text {UTS }}$ values for UD-Epoxy-CFRP and UD-PPS-CFRP are quite close to the experimental values, although the estimate for UD-PA6-CFRP is somewhat higher. For UD-PEEK-CFRP, the estimated $\sigma_{\mathrm{UTS}}$ was much lower than its experimental value. To understand the low accuracy of this estimation, particularly for the thermoplastic CFRPs, the failure characteristics of the CFRPs were examined.

Figure 8 shows the UD- and CR-CFRPs after the tensile tests. For the UD-CFRPs (Figure 8a), different fracture modes were observed, depending on the CFRP. The Epoxy-CFRP plates fractured in different directions in a hedgehog-like pattern. For PA6 and PPS, the specimens fractured completely into two pieces. In contrast, UDPEEK-CFRP did not break completely, with the fibers instead being pulled out from the resin. These distinct failure modes of the UD-CFRPs were in contrast to that of the CR-CFRPs. Figure $8 \mathrm{~b}$ shows photographs and SEM images of the CR-CFRPs after the tensile test. It is clear that all of the CR-CFRPs fractured in a similar manner and that, on a micro-scale, as can be seen from the SEM images, CFs were delaminated clearly from the resin for all of these samples. The delamination is able to grow mainly as a consequence of fiber/matrix interfacial debonding. The fracture characteristics of the UD- and CR-CFRPs indicate that it should be possible to alter their tensile strength, especially for UD-PEEK-CFRP. To understand this further, the extent of wetting of the CFs was examined, with the wettability of CFs being quantified by the bending strength as shown in Figure 1c, i.e., the peeling strength (bonding strength) between the $\mathrm{CF}$ and resin. The mean bending strengths obtained using this approach were $20 \mathrm{MPa}$ for PEEK-CFRP, $37 \mathrm{MPa}$ for Epoxy-CFRP, and $107 \mathrm{MPa}$ for PA6-CFRP. Because of the low bending strength of PEEK-CFRP, its wettability will be lower, resulting in its low $\sigma_{\mathrm{UTS}}$.

To estimate the ultimate tensile strength more accurately, a multiple regression analysis was carried out. In this analysis, various material parameters were employed, including fracture strain $\varepsilon_{\mathrm{f}}$, elastic constant $E$ (GPa), wettability (bending strength $\sigma_{\mathrm{b}}$, MPa), Vickers hardness $\mathrm{Hv}$, and CF condition $\alpha$ (with $\alpha=1$ for UD and $\alpha=2$ for $\mathrm{CR}$ ). The details of the material properties examined are summarized in Table 2 . This analysis revealed a high correlation rate of more than 0.9 , and gave the following approximation equation:

$$
\sigma_{\mathrm{UTS}}=795 \varepsilon_{\mathrm{f}}+0.69 \mathrm{E}+1.12 \sigma_{\mathrm{b}}+2.54 \mathrm{HV}-928 \alpha+428 .
$$

Figure 9 shows the relationship between the experimental tensile strengths (Figure 3 ) and the values obtained from Eq. 2 for both UD- and CR-CFRPs. It is clear that the multiple regression analysis results for all the CFRPs are in good agreement with the experimentally obtained tensile strength. Hence, this estimation method may prove useful for assessing the ultimate tensile strengths of CFRPs.

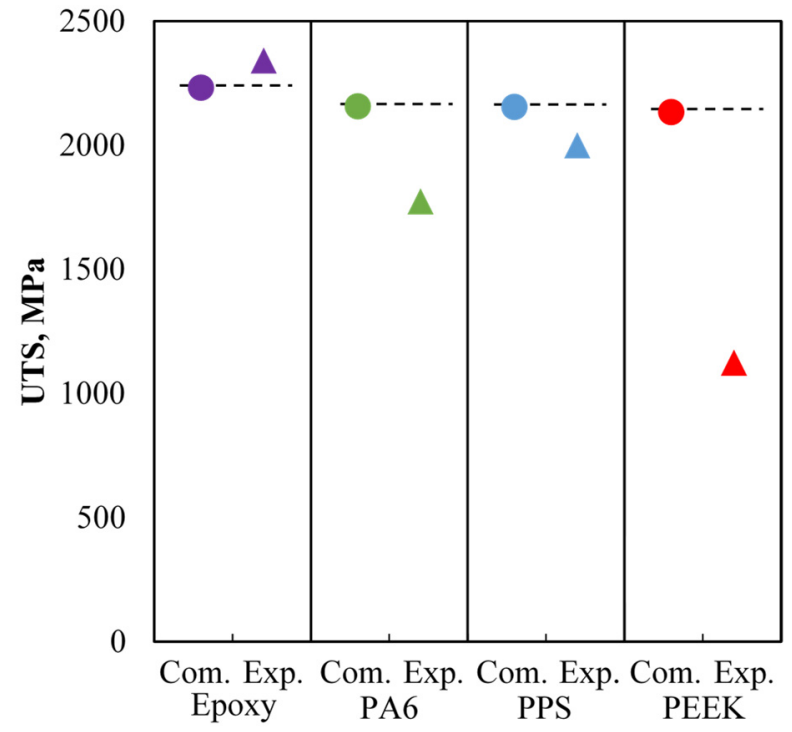

Figure 7. Tensile strengths of CFRPs as estimated by the compound law 
(a) UD-CFRP

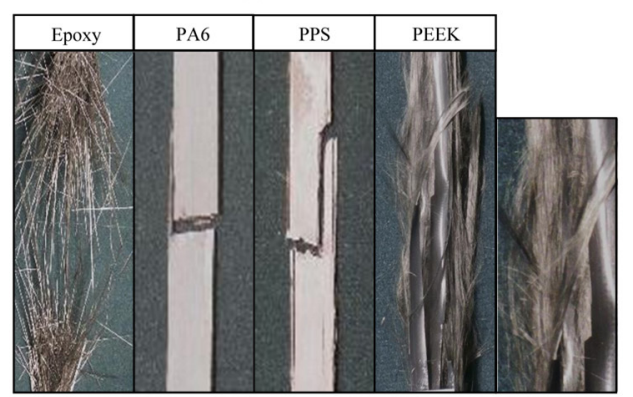

(b) CR-CFRP

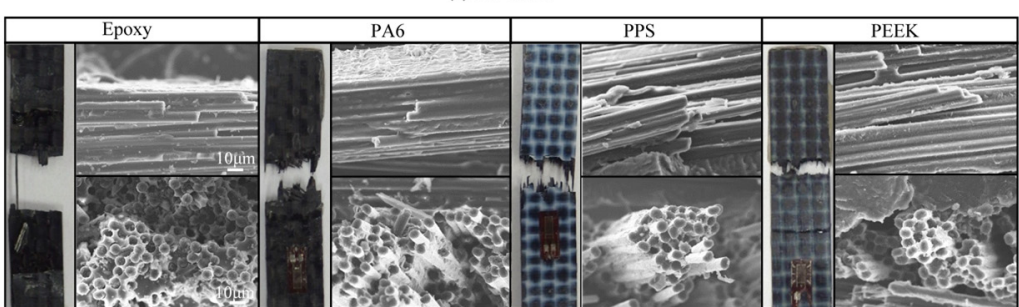

Figure 8. (a) Photographs of failed UD-CFRP samples after tensile tests. (b) Photographs of failed CR-CFRP samples and SEM images of fracture surfaces after tensile tests

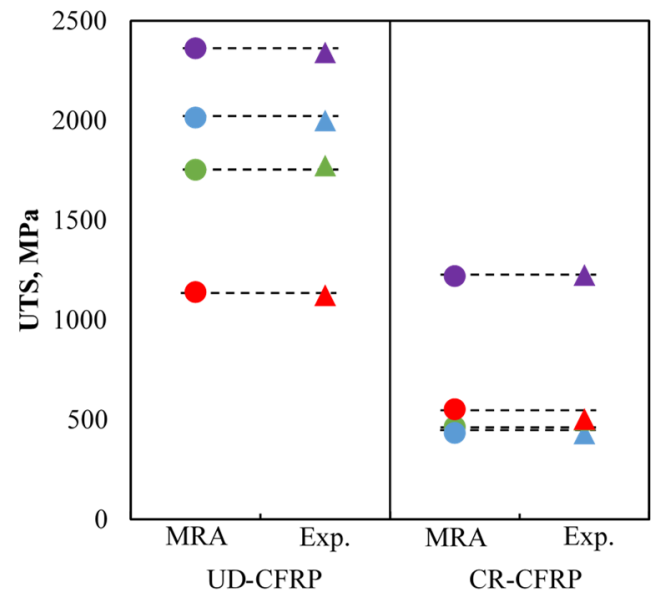

Figure 9. Tensile strength values estimated numerically by multiple regression analysis (MRA) compared with experimental values (Exp.)

Table 2. Mechanical and material properties of UD- and CR-CFRPs

\begin{tabular}{|c|c|c|c|c|c|c|c|}
\hline & & $\begin{array}{c}\text { Breaking } \\
\text { strain }\left(\varepsilon_{\mathrm{f}}\right), \%\end{array}$ & $\begin{array}{c}\text { Elastic } \\
\text { modulus }(E), \mathrm{GPa}\end{array}$ & $\begin{array}{l}\text { UTS for resin } \\
\left(\sigma_{\text {UTS }} r\right), \mathrm{MPa}\end{array}$ & Bending strength $\left(\sigma_{\mathrm{b}}\right), \mathrm{MPa}$ & Vickers hardness (Hv) & $\mathrm{UD} 1$ or $\mathrm{CR} 2(X)$ \\
\hline \multirow{4}{*}{ UD } & EPOXY & 0.8 & 309 & 283 & 37 & 49.9 & 1 \\
\hline & PA6 & 0.8 & 213 & 38 & 107 & 7.1 & 1 \\
\hline & PPS & 0.9 & 212 & 91 & 23 & 35.9 & 1 \\
\hline & PEEK & 0.6 & 166 & 96 & 20 & 38.1 & 1 \\
\hline \multirow{4}{*}{$\mathrm{CR}$} & EPOXY & 1.8 & 69 & 283 & 608 & 49.9 & 2 \\
\hline & PA6 & 1.8 & 25 & 38 & 305 & 7.1 & 2 \\
\hline & PPS & 1.3 & 39 & 91 & 411 & 35.9 & 2 \\
\hline & PEEK & 1.1 & 46 & 96 & 576 & 38.1 & 2 \\
\hline
\end{tabular}




\section{Conclusions}

The mechanical properties of various carbon fiber reinforced plastics have been examined experimentally and numerically: unidirectional (UD) and crossply (CR) CFRPs with different resins, namely, epoxy, polyamide (PA6), polyphenylene sulfide (PPS), and polyether ether ketone (PEEK). The following conclusions can be drawn from the results:

1) The tensile and fatigue strengths of UD-CFRPs were more than twice as high as those of the CR-CFRPs, even though the latter exhibited high ductilities. These high ductilities can be attributed to the crosslinking fiber effect and the low volume fraction of CF in the loading direction.

2) The mechanical properties of CFRPs based on thermoset resin were overall higher than those of the thermoplastic-based CFRPs. Epoxy-CFRP had a high tensile strength, about twice that of PEEK-CFRP. On the other hand, relatively high tensile strengths were found for PPS- and PA6-CFRP, about $90 \%$ of the value for Epoxy-CFRP.

3) The conventional compound law was found to be inappropriate for estimating the tensile strength, especially for thermoplastic and CR-CFRPs, owing to the different wettability arising from a different failure mode, namely, pulling out and delamination of CFs. The $\sigma_{\mathrm{UTS}}$ value depended not only on the tensile strengths of the $\mathrm{CF}$ and resin, but also on various material properties, including the wettability of CF by resin. On the basis of the material properties, the tensile strengths of various UD- and CR-CFRPs were found to be well estimated numerically using statistical analysis.

\section{References}

Belingardi, G., Koricho, E. G., \& Martorana, B. (2011, November). Design optimization and Implementation of composite and recyclable thermoplastic materials for automotive bumper. In Proceedings of Fifth International Conference on Advanced Computational Methods in Engineering (ACOMEN 2011), Liege, Belgium (pp. 14-17).

Bos, G. (2002, May). EU waste legislation and the composites industry. In Seminar on recycling of composite materials, IFP SICOMP, Molndal, Sweden (Vol. 14).

Curtis, P. T. (1984). The effect of edge stresses on the failure of $(0,45,90)$ CFRP laminates. Journal of materials science, 19(1), 167-182.

Eguemann, N., Giger, L., Roux, M., Dransfeld, C., Thiebaud, F., \& Perreux, D. (2013, January). Compression moulding of complex parts for the aerospace with discontinuous novel and recycled thermoplastic composite materials. In 19th International Conference on Composite Materials (pp. 1-11).

Kirihara, T., Kawashima, T., Takahashi, J., Matsuo, T., \& Uzawa, K. (2011). Demand and disposal forecast for carbon fibre by bottom-up approach. In Proceedings of 18th Int. Conf. Comp. Mater. TH32 (2011-8) (pp. 14).

Ku, H., Wang, H., Pattarachaiyakoop, N., \& Trada, M. (2011). A review on the tensile properties of natural fiber reinforced polymer composites. Composites Part B: Engineering, 42(4), 856-873.

Liang, J. Z. (2005). Tensile and flexural properties of hollow glass bead-filled ABS composites. Journal of Elastomers \& Plastics, 37(4), 361-370.

Ogi, K., Nishikawa, T., Okano, Y., \& Taketa, I. (2007). Mechanical properties of ABS resin reinforced with recycled CFRP. Advanced Composite Materials, 16(2), 181-194.

Ogihara, S., \& Takeda, N. (1995). Interaction between transverse cracks and delamination during damage progress in CFRP cross-ply laminates. Composites Science and Technology, 54(4), 395-404.

Okayasu, M., \& Kondo, Y. (2018). Tensile Properties of Unsaturated Polyester and Epoxy Resin Reinforced with Recycled Carbon-Fiber-Reinforced Plastic. Applied Composite Materials, 25(3), 561-568.

Okayasu, M., Yamazaki, T., Ota, K., Ogi, K., \& Shiraishi, T. (2013). Mechanical properties and failure characteristics of a recycled CFRP under tensile and cyclic loading. International Journal of Fatigue, 55, 257-267.

Pannkoke, K., Oethe, M., \& Busse, J. (1998). Efficient prepreg recycling at low temperatures. Cryogenics, 38(1), 155-159.

Suresh, A., Harsha, A. P., \& Ghosh, M. K. (2009). Solid particle erosion of uunidirectional fiber reinforced thermoplastic composites. Wear, 267, 1516-1524. 
Taj, S., Munawar, M. A., \& Khan, S. (2007). Natural fiber-reinforced polymer composites. Proceedings-Pakistan Academy of Sciences, 44(2), 129-144.

Takahashi, J., Matsutsuka, N., Okazumi, T., Uzawa, K., Ohsawa, I., .. Kitano, A. (2007). Mechanical properties of recycled by injection molding method. Proceedings of 16th Int Conf. Comp. Mater. FrFA2-02, 1-6.

Uzawa, K., Takahashi, J., Kageyama, K., Uno, H., Okazumi, T., \& Ohsawa, I. (2009). Improvement in the impact energy absorption of recycled CFRP. In Proceedings of 17th int Conf Comp Mater A (Vol. 3, pp. 2009-7).

\section{Copyrights}

Copyright for this article is retained by the author(s), with first publication rights granted to the journal.

This is an open-access article distributed under the terms and conditions of the Creative Commons Attribution license (http://creativecommons.org/licenses/by/4.0/). 